\title{
Crianças com problemas orgânicos: contribuições e riscos de prognósticos psicológicos
}

\section{Children with organic problems: contributions and risks of psychological prognoses}

\author{
Cecília Guarnieri Batista*
}

\begin{abstract}
RESUMO
São apresentadas reflexões sobre as práticas dos profissionais de saúde e educação, voltadas para crianças com problemas orgânicos, e que podem apresentar alterações em seu desenvolvimento psicológico. Casos de crianças com deficiência visual, muitas com problemas orgânicos adicionais, são analisados no que se refere às contribuições de profissionais de saúde e educação para a promoção do seu desenvolvimento, sob uma perspectiva inclusiva, e discutidos os riscos de prognósticos negativos desses profissionais. São destacados os seguintes momentos de atuação: Orientação para "estimulação" nos primeiros anos de vida, Avaliação nos anos préescolares e início da escolarização, e Orientação familiar nos anos préescolares e início da escolarização. Quanto ao item Orientação familiar, são destacados para discussão os seguintes itens: a) exagero dos pais quanto à gravidade do problema orgânico; b) oferta de compensações à criança, em virtude do problema; e c) não aceitação dos limites momentâneos da criança, quanto à possibilidade de aquisições específicas (o que não significa a impossibilidade dessa aquisição). Finalmente, os casos apresentados são considerados como indicação de conflito entre modelos organicistas versus modelos centrados nos aspectos psicológicos e sóciohistóricos da construção da deficiência. É discutida a questão da genera-
\end{abstract}

" Professora Doutora, docente do Centro de Estudos e Pesquisas em Reabilitação "Prof. Dr. Gabriel O. S. Porto" (Cepre), Faculdade de Ciências Médicas (FCM), Unicamp. E-mail: cecigb@fcm.unicamp.br 
lidade versus especificidade da atenção, destacando-se a necessidade de acompanhamento da história das interações da criança com seus familiares e outras pessoas significativas, além da orientação quanto a recursos ligados a cada tipo de deficiência. Sugere-se a continuidade da discussão sobre modos de encorajar o desenvolvimento nas crianças com problemas de origem orgânica, superando-se os limites dos modelos organicistas. Palavras-chave: deficiência e prognóstico psicológico, deficiência e inclusão social, problemas orgânicos e desenvolvimento psicológico.

\begin{abstract}
The present study presents reflections about professional practices in the areas of health and education, centered in the experience with children with organic problems, who may present alterations in their psychological development. The analysis is centered in children with visual impairment, which is associated, in many cases, to additional organic problems. The contributions of health and education professionals for the promotion of development of those children, as well as the risks of negative prognoses, are discussed under the perspective of social inclusion. The following topics are discussed: Parent guidance in early intervention, Assessment procedures in preschool and school years, and Family guidance in preschool and school years. This last topic is analyzed in terms of: a) parents overestimation of the risks of the organic problems of the child; b) trials of compensating the child for his/her organic problems; c) denial of evidences of present limits for the learning of specific topics. Finally, the cases are considered as indication of conflicts between biologically based versus psychologically, historically and culturally based conceptions about deficiency. The matter of specificity of attention is discussed, emphasizing the need of continuously following the history of the interactions of the child with his/her family and other significant persons, besides the offer of general guidance on resources for each kind of disability. The permanent discussion about strategies of developmental promotion in children with organic problems is suggested, overcoming the limits of biologically based models.
\end{abstract}

Key-words: deficiency and psychological prognosis, deficiency and social inclusion, organic problems and psychological development.

O presente trabalho traz algumas reflexões sobre as práticas dos profissionais de saúde e educação, voltadas para crianças com problemas orgânicos, e que podem apresentar alterações em seu desenvolvimento psicológico. Está baseado nas experiências da autora na condução de um projeto integrado 
de pesquisa e intervenção para promoção do desenvolvimento de crianças com diagnóstico de deficiência visual (baixa visão ou cegueira) ${ }^{1}$, junto ao Programa Infantil DV de um centro universitário que atua em pesquisa, ensino e atendimento de pessoas com deficiência visual e surdez.

Esse projeto, descrito com mais detalhe em BATISTA (1998), envolve o atendimento das crianças em pequenos grupos, em sessões semanais de $90 \mathrm{mi}-$ nutos, com atividades diversificadas, envolvendo tarefas de representação em suas várias modalidades (ex: ouvir e contar histórias, desenhar, ler), e tarefas ligadas a conhecimentos sociais e lógico-matemáticos. Essas tarefas são apresentadas para incentivar e conhecer os estilos de aprendizagem das crianças, sem características de reforço escolar. Envolve, ainda, atividades de recreação livre e dirigida, em sala e em área externa com parquinho. São realizadas, também, reuniões quinzenais, em grupo, com as mães ou familiares responsáveis pela criança, e são mantidos contatos com professores e orientadores da escola em que a criança estuda. As atividades realizadas são registradas sistematicamente na forma de relatos de sessão, sendo, também, realizadas filmagens em vídeo, para o desenvolvimento de subprojetos específicos.

As crianças atendidas, com diagnóstico inicial de deficiência visual, critério para elegibilidade nas atividades do Programa Infantil DV, apresentam, em muitos dos casos, outros problemas de origem orgânica, tais como alterações neurológicas (epilepsias, malformações, microcefalia, lesões por toxoplasmose ou outros fatores), síndromes que incluem possíveis problemas neurológicos, e sequielas da prematuridade.

A promoção do desenvolvimento é vista em uma perspectiva de inclusão escolar e social, de acordo com recentes postulações de autores da área. O conceito de educação inclusiva é apresentado por LIPSKY e GARTNER (1999) como um requisito para uma sociedade democrática. Os autores apresentam um quadro comparativo elaborado por Keating, sobre as características da educação na Era Industrial e na Era da Informação. Segundo este quadro, a Era Industrial é caracterizada por uma pedagogia voltada para a transmissão de conhecimento, tendo como objetivos educacionais a apreensão conceitual para poucos, e o desenvolvimento de habilidades básicas para todos. Nesse contexto, a diversidade é vista como inerente à pessoa e classificável em categorias distintas e estáveis. A abordagem a essa diversidade se faz por meio de políticas de oferta do básico para a população em geral e da seleção de elites para uma educação diferenciada.

\footnotetext{
${ }^{1}$ Projeto aprovado pelo Comitê de Ética da FCM.
} 
Já a Era da Informação é caracterizada por uma pedagogia de construção do conhecimento, tendo como objetivos educacionais a apreensão conceitual e a construção do conhecimento para todos. A diversidade é vista como sujeita a alterações e determinada por condições históricas. E a abordagem a essa diversidade se processa por meio de um modelo de desenvolvimento de aprendizagem ao longo de toda a vida, para toda a população.

Para LIPSKY e GARTNER (1999), a promoção da inclusão é vista como requisito para uma sociedade democrática, e como o oposto à alienação, que ameaça a comunidade. Dewey é lembrado na seguinte citação:

"Dado que os humanos precisam aprender a ser democráticos, a política social - e particularmente a política educacional - deve promover sistemas inclusivos, porque esses são os tipos de arranjo institucional em que as identidades democráticas, valores, e comunidades são cultivados" (LIPSKY; GARTNER, 1999, p. 21).

O conceito de inclusão social, além da questão escolar, abrange, também, questões relativas à acessibilidade em todos os níveis, o que significa, entre outros aspectos, o planejamento de ambientes acessíveis, a adoção de políticas de empregabilidade, de lazer e de transportes, que realmente signifiquem acesso para pessoas com deficiência.

Há uma extensa literatura discutindo a produção social da deficiência. São citados exemplos em que uma pessoa é considerada deficiente apenas devido a um parâmetro social rígido que, removido, também remove o rótulo de deficiente. No presente estudo, pretende-se abordar a questão do ponto de vista da atuação dos profissionais que compõem as equipes dos serviços de saúde e educacionais e que, em diferentes momentos da vida da criança com deficiência, são defrontados com situações cuja solução pode significar um passo na direção da inclusão ou, ao contrário, reduzir as chances de uma participação social mais ampla dessa criança.

O acompanhamento sistemático do processo de desenvolvimento dessas crianças, muitas vezes por vários anos, tem tornado possível a discussão dessa questão. Ao longo do trabalho, uma das constatações, em relação a várias das crianças, refere-se às alterações em seu desenvolvimento, que assumem várias formas, conforme descrito em BATISTA (2001), incluindo: pouco domínio dos conhecimentos habitualmente esperados para a idade (desenho, leitura e escrita, conhecimentos sociais e matemáticos), dificuldade de atenção concentrada e de reflexão sobre tarefas com conteúdo cognitivo, falta de respeito a regras sociais (alternância de turnos, compartilhamento de materiais, p. ex.), recusa de participação em diferentes atividades propostas, coordenação motora pobre, dificultando o manuseio do lápis e de materiais de encaixe 
e, no caso das crianças cegas, pouco desenvolvimento do sentido háptico (tato ativo).

A discussão sobre as origens dessas dificuldades no referido trabalho (вAтіSTA, 2001) indicou como possibilidades: serem decorrentes de problemas orgânicos adicionais à deficiência visual; e/ou serem o resultado de restrição de oportunidades na família e na comunidade; e/ou serem conseqüência de interações insatisfatórias na escola. Não foi considerada como hipótese explicativa a deficiência visual per se e, em especial, a cegueira, uma vez que foram observadas crianças cegas sem essas alterações, especialmente no que se referia às capacidades cognitivas. Foram confirmadas, assim, as postulações de vários autores, incluindo VYGOTSKY $(1934 ; 1997)$ e WARREN (1994), de que os problemas observados em pessoas cegas não são inerentes à condição da cegueira. Consideramos, assim, que os problemas eram decorrentes, principalmente, de interações insatisfatórias ou problemáticas com familiares e outros membros da comunidade, bem como de interações na escola, que não favoreciam seu desenvolvimento cognitivo, social e afetivo.

Um comentário especial deve ser feito para o primeiro item, relativo aos problemas orgânicos adicionais à deficiência visual. De acordo com as atuais concepções sobre as relações entre o biológico e o cultural, em que o ser humano é visto como "biologicamente cultural" (BUSSAB; RIBEIRO, 1998), não se pode pensar em fatores de origem orgânica atuando como determinantes per se, mas sim na interação entre fatores. É bastante esclarecedora a concepção de deficiência primária e secundária, que é analisada, entre outros, por AMARAl (1996). A autora retoma a definição de deficiência da Organização Mundial da Saúde, subdividida em três termos, e considera como deficiência primária os conceitos de deficiência (impairment) e incapacidade (disability), e como deficiência secundária, o conceito de desvantagem (handicap). Afirma a autora: "Como se vê, a conceituação objetiva e universal só é possível para a deficiência primária, sendo a deficiência secundária passível de leituras específicas, em função do binômio espaço-tempo. Mas, mais que isso, mesmo que irreversíveis e não compensáveis, como já dito, as limitações ligadas à deficiência primária por si só não impedem realmente o desenvolvimento e a vida plena, considerando-se apenas forma e ritmo específicos. Inversamente, reconhece-se que a deficiência secundária pode impedir esse desenvolvimento e essa vida plena, ao aprisionar a pessoa numa rede que poucas vezes tem a ver com a deficiência propriamente dita: a rede constituída e constituidora das barreiras atitudinais. Refiro-me a preconceitos, estereótipos e estigma, que são os fenômenos psicossociais que circundam a questão da deficiência." (AMARAL, 1996, p. 9). 
Pensamos que existe uma razoável clareza de como isso se passa no caso da cegueira, no que se refere ao processo de escolarização. A lesão ocular (deficiência) impede a visão (incapacidade) e, conseqüentemente, a leitura e escrita convencionais (desvantagem). Essa desvantagem pode ser muito reduzida, ou mesmo eliminada, com a adoção de formas alternativas de acesso à leitura e escrita (sistema Braille, softwares sonoros). Quanto aos recursos para pessoas com deficiência visual, existem muitas soluções bem desenvolvidas. Os problemas centrais se referem à falta de políticas públicas que favoreçam, de fato, o acesso, em quantidade e qualidade, a esses recursos. Entretanto, há situações para as quais as próprias postulações teóricas estão menos claras, especialmente no que se refere à presença de certos problemas de origem orgânica e/ou de certas condições de alterações no desenvolvimento, tais como síndromes e alterações neurológicas que levem a dificuldades de aprendizagem, agitação, etc. É o que nos propomos a abordar, pelo menos parcialmente, no presente trabalho, no que se refere às possibilidades de atuação dos profissionais de saúde e educação. A análise dos casos acompanhados nos permitiu identificar alguns exemplos de contribuições e, por outro lado, de situações de risco, a partir de prognósticos quanto ao desenvolvimento psicológico, explícitos ou implícitos na atuação profissional.

\section{Orientação para "estimulação" nos primeiros anos de vida}

Uma série de evidências tem indicado que vários "programas de estimulação" são bastante focados nos objetos e atividades a serem oferecidos. No caso de crianças com deficiência visual, muitos materiais vêm sendo apontados e indicados para o trabalho com a criança. Entretanto, ao transmitir essas informações, muitas vezes falta abordar a questão da sensibilidade dos pais para a interação com seu filho. Não se trata de orientá-los para cumprir tarefas, às vezes até quantificadas (especificando-se "lições" ou quantidade de momentos de "treino"), mas de estar sensível para os interesses e para a disposição da criança. As qualidades da interação mãe-bebê já foram destacadas por ROSSETTI-FERREIRA (1979), em revisão de literatura em que destaca a importância de um relacionamento sintônico, sincrônico e recíproco. A sintonia é descrita como "sensibilidade e disposição para perceber qualquer mudança no comportamento da outra pessoa, usando as pistas assim percebi- 
das para orientar suas próprias respostas" (p. 40-41), e a sincronia, como "o estado de coisas em que os comportamentos de dois indivíduos tornam-se mutuamente dependentes; onde as respostas de um tornam-se pistas para o comportamento do outro" (CAIRNS, apud ROSSETTI-FERREIRA, 1979, p. 41). Ainda segundo a autora, "a qualidade de reciprocidade implica que a relação é bilateral, entre a mãe e a criança" (p. 40). De acordo com essas colocações, para uma interação de qualidade não basta, portanto, apresentar os objetos. É preciso criar uma situação de interação em que a criança esteja à vontade, interessada, e participando efetivamente da "dança" interativa. Aí se tem uma situação comunicativa, com afetividade positiva, e que provavelmente favoreça diferentes exemplos de aprendizagem. Além disso, é bom lembrar que a compreensão das aquisições infantis não se esgota nas relações diádicas mãecriança ou criança-objeto. É mais abrangente a proposta de triangulação: criança - adulto mediador - objeto, "o mágico número três", conforme postulado por RODRÍGUEZ e MORO (1999).

Um dos casos que estamos atendendo evidenciava uma situação em que a mãe, inicialmente, parecia pouco sensível aos sinais comunicativos de sua filha, o que foi mudando, gradualmente, ao longo do processo de intervenção.

$\mathrm{Júlia}^{2}$ passou a ser atendida em nosso projeto quando tinha quatro anos, ao final de 2002. Era cega congênita, vivia com os pais e um irmão mais velho, estando a renda da família na faixa abaixo de três salários mínimos. Não tinha fala contextualizada (não se dirigia às pessoas nem respondia a perguntas, mas cantarolava pronunciando palavras e, ao protestar, às vezes falava frases, como: "Não quer!", ou "Vai cair!"), não aceitava objetos oferecidos para toque, apresentava movimentos repetitivos (com a boca, e mordidas não convencionais e tensas da chupeta) e tinha crises de birra (gritos, tensão muscular) aparentemente sem explicação. Não havia informações de problemas neurológicos, embora fosse atendida em um serviço universitário desde pequena. Nos primeiros contatos, a mãe não era capaz de descrever, em relação à menina, gostos ou preferências, nem mesmo quanto à alimentação. Apenas dizia que ela gostava de música e que cantarolava em casa. Ao longo das sessões realizadas, Júlia passou a permanecer com um dos membros da equipe, aceitando colo, raros contatos com objetos, ouvindo músicas infantis e raras vezes cantarolando, brincando de roda (girando sobre si mesma, segurando a mão da mediadora) e aceitando a orientação para bater palmas (suas mãos em posição externa em relação às da mediadora). Sua mãe começou a

${ }^{2}$ Os nomes das crianças são fictícios. 
relatar que ela estava cantarolando as mesmas músicas em casa, que estava se locomovendo apoiando-se nas paredes e explorando vários objetos que encontrava. Mais recentemente, Júlia passou a interagir com outros membros da equipe: passou a manusear carrinhos e tambores, de forma repetitiva, mas apresentando um contato com objetos anteriormente inexistente. Ao final do primeiro semestre de 2003, dava mostras claras de gostar de brincar de roda e de girar. Aceitava ser colocada no escorregador, rindo muito e fazendo movimento corporal de ser pega para ser novamente erguida e colocada no alto. As birras foram bastante reduzidas. Sua mãe passou a trazer relatos que demonstravam maior sensibilidade a mudanças no comportamento de Júlia, indicativas de gostos e preferências, e passou a relatar exemplos de situações em que ela brincava com o irmão e com o pai.

É claro que se trata de um caso particularmente difícil, de criança cujas alterações não são explicáveis apenas pela cegueira, conforme discutido anteriormente, não se dispondo, ainda, de hipóteses sobre sua origem. Entretanto, ilustra a questão da orientação familiar nos primeiros anos, e da complexidade que pode assumir, muito além do que é normalmente preconizado. $\mathrm{E}$ mostra o risco de um prognóstico desfavorável, ao invés de tentativas de "quebra" do círculo vicioso das dificuldades de interação. Não se sabe, ainda, quanto de progresso será obtido com Júlia. Entretanto, a experiência de pouco mais de um semestre de atendimento indicou uma alteração em seu padrão de contato com pessoas estranhas, e uma mudança na forma como sua mãe a descreve e se refere a ela.

\section{Avaliação dos anos pré-escolares e início da escolarização}

A questão da avaliação cognitiva por meio de testes formais de inteligência constitui-se em extenso capítulo da Psicologia, com muitos prós e contras. O que se pretende, neste item, é discutir os riscos de sua utilização para fundamentar decisões sobre colocação escolar (escola regular ou instituição especializada) em crianças pré-escolares com alterações no desenvolvimento.

Será apresentado o caso de Gisela, para ilustrar a questão. Gisela começou a ser atendida no projeto em maio de 2002. Tinha seis anos, baixa visão profunda e calcificações cerebrais devido a infecção congênita. Morava com a mãe e irmã mais velha, e próxima de outros parentes da mãe. A renda fami- 
liar era inferior a três salários mínimos. Tinha freqüentado a Apae quando pequena, e havia ingressado e saído de uma pré-escola no início de 2002, em circunstâncias que não ficaram claras pelo relato da mãe. Após o ingresso no projeto, sua mãe a matriculou em outra pré-escola regular, perto de sua casa, e iniciou-se contato com a nova professora, que estava assustada pois the disseram que ia receber uma criança "cega e DM" (sic). Como Gisela às vezes não permanecia na tarefa proposta, e, com certa freqüência, começava a gritar (uma forma de excitação, não necessariamente quando contrariada), a professora pensou que suas suspeitas estavam confirmadas. Entretanto, foi gradualmente verificando a capacidade de adaptação e aprendizagem de Gisela, periodicamente relatadas para nós.

No segundo semestre, Gisela participou de nosso projeto de pesquisa relativo a avaliação cognitiva. Os resultados obtidos indicaram:

1- Avaliação formal de inteligência: QI de 67 (WISC verbal, padronização brasileira de LEMGRUBER e PAINE, 1981).

2- Avaliação do desempenho escolar em grupo: Na avaliação realizada em agosto, mostrou as seguintes capacidades: nomeação de cores; identificação de algumas letras, com mais constância para a letra inicial de seu nome; recitação da seqüência dos números até 7 sem correspondência.

3- Avaliação assistida de contagem: Apresentou acertos e erros ao recitar a sequiência numérica até 10 , sem regularidade. Precisou de orientação para fazer correspondências, acertando partes de seqüências de contagem de objetos. Passou a mostrar mais atenção à tarefa do que nas situações de avaliação em grupo.

4- Busca de "espertezas": uma outra forma de avaliação referiu-se à observação sistemática das crianças durante as sessões, para o registro de exemplos de "espertezas", ou seja, de ocorrências em que se pudesse identificar a presença de habilidades cognitivas. Dentre os exemplos para Gisela, transcrevem-se os seguintes:

- Quando o adulto coordenador estava ditando palavras para Nivaldo e falou "rinoceronte", Gisela falou "Quindim" (rinoceronte do Sítio do Picapau Amarelo) e lembrou-se de outros personagens do Sítio (história que ela ouviu em outro lugar, não nesse grupo do projeto).

- Na brincadeira no tapete, Gisela brincou com a caixa de objetos de cozinha, brincou de servir suco para as crianças e os adultos, brincou de passar a roupa das pessoas e secou o cabelo de todos com o secador. 
- Ao ouvir uma história sobre galinha e seus pintinhos, falou: "Minha mãe não cria pintinhos, cria eu".

Dessa forma, em situações informais, sem a exigência da atenção concentrada própria dos procedimentos de avaliação, Gisela mostrou várias capacidades: estabelecimento de analogias, conhecimento de papéis e tarefas cotidianas, e, em outros exemplos não transcritos, de memorização e reprodução de canções, e de compreensão da estrutura do grupo (p. ex., sempre perguntando de uma criança que estava faltando por várias sessões).

Considera-se que a tarefa, ao longo desse ano, foi identificar capacidades em Gisela, o que era difícil dado seu comportamento agitado, de pouca atenção às tarefas (inclusive realizando-as sem examinar o material apresentado), e de proposta constante de mudança de atividade. Ao final do ano, a sugestão era de que ela permanecesse na escola regular, mas que se buscasse um mecanismo para sua permanência por mais um ano na pré-escola, de forma a que ela estivesse mais preparada, em termos de posturas em sala de aula, para uma $1^{a}$ série do ensino fundamental, o que estava sendo aceito pela escola.

Nesse período, sua mãe procurou um serviço de neurologia para avaliação periódica, e solicitou aconselhamento sobre o tipo de escola que Gisela deveria freqüentar. Havia pressões familiares para que ela voltasse para a Apae, e a mãe hesitava entre essas pressões e a opinião de nossa equipe, de permanência na pré-escola regular. A posição desse serviço de neurologia, apresentada pela psicóloga da equipe em laudo enviado à escola, foi de que não era possível aplicar testes convencionais de inteligência em Gisela, que sua idade social correspondia a três anos, e deixava ambígua a questão da escola especial. Após uma série de contatos entre as partes envolvidas (nossa equipe, a equipe do serviço de neurologia, e a escola), acabou ficando acertada a permanência de Gisela na pré-escola regular em 2003. Sua professora permaneceu a mesma, e ela prosseguiu com novas aquisições ao longo do primeiro semestre de 2003, em um processo de adaptação cada vez melhor à escola.

Não vamos entrar, aqui, na questão das reformulações na escola atual, necessárias para propiciar uma verdadeira inclusão. Dadas as condições de desenvolvimento de Gisela, naquele momento, a pré-escola em que ela já estava pareceu-nos oferecer melhores condições para seu processo de escolarização, do que as outras opções disponíveis (Apae ou $1^{\text {a }}$ série do ensino regular).

O ponto a ilustrar é o da contraposição entre modos de avaliação das habilidades cognitivas: de um lado, os dados obtidos por meio de avaliações formais, em procedimentos de curta duração e, de outro, os dados obtidos por observações sistemáticas de longo prazo. A questão, já explicitada em outros estudos de nosso grupo (entre outros, BATISTA; NUNES; HORINO, 2002) é que, no 
caso de crianças com alterações semelhantes às descritas, as abordagens de avaliação mais formalizada, mesmo na modalidade assistida, fornecem um perfil inferior ao das reais capacidades da criança, que já se caracteriza como defasada. Daí para um prognóstico desfavorável, e para encaminhamentos que dificultem sua inserção escolar e social, é um pequeno passo. Pensamos que aí reside uma das origens da construção social da deficiência. Não se trata de preconceitos vagamente localizados "na sociedade", mas, em muitos casos, de ações profissionais com alto teor de respeitabilidade, como têm sido os laudos baseados em avaliações formais.

\section{Orientação familiar nos anos pré-escolares e início da escolarização}

Uma outra questão a ser apontada refere-se às modalidades de atendimento oferecidas a esse tipo de população. Gostaríamos de destacar alguns dos problemas que desafiam as equipes profissionais, quanto à adequada orientação dos casos. São situações que podem significar marcos na inserção social da criança ou, ao contrário, contribuir para a "fabricação da deficiência", e que exigem atenção e perspicácia das equipes profissionais. Entre os problemas que têm chamado nossa atenção, incluem-se: a) exagero dos pais quanto à gravidade do problema orgânico; b) oferta de compensações à criança, em virtude do problema; e c) não aceitação dos limites momentâneos da criança, quanto à possibilidade de aquisições específicas (o que não significa a impossibilidade dessa aquisição).

a) Exagero dos pais quanto à gravidade do problema orgânico:

É importante deixar claro o reconhecimento de que crianças com problemas de origem orgânica podem precisar de atenção especial: medicação, consultas periódicas, cuidados com a segurança, algumas restrições quanto a atividades permitidas. Algumas dessas restrições podem significar limitações no entrosamento com colegas e amigos, e na participação em algumas atividades escolares e de lazer. É papel das equipes profissionais e dos educadores discutir alternativas para minimizar esses impedimentos, com formas engenhosas e alternativas de execução das atividades. Dessa forma, pode-se caminhar na direção da redução das desvantagens, e da verdadeira inclusão. 
Por outro lado, constituem-se situações de risco aquelas em que os problemas são amplificados e exagerados. Um caso que acompanhamos por vários anos foi o de Lúcio, um menino com baixa visão moderada e com episódios esporádicos de convulsão atípica (a mãe dizia que estas ocorriam cada vez de uma forma, mas, indagada, reconhecia que praticamente não ocorriam, e que tinham características de crise de ausência, às vezes com lábios arroxeados). Ele havia nascido prematuro (1750g), era filho único, sua família tinha renda acima de 10 salários mínimos. Seu QI (WISC verbal) estava na faixa de 100 a 105 e sua participação em nosso projeto indicava vivacidade e capacidade de aprender. Sua mãe era excessivamente preocupada com ele, vendo-o sempre como doente. Quando ele cursava o pré, em escola particular, a recomendação era de que, se ele tivesse crise, que se comunicassem imediatamente com ela, que o levaria de imediato ao pronto-socorro. Isso contrariava as orientações dos neurologistas, que sugerem manter a criança em local calmo e observá-la, especialmente no caso de crises de ausência. De fato, os professores dessa escola nunca tinham presenciado uma crise.

Quando Lúcio foi para a $1^{\mathrm{a}}$ série, sua mãe escolheu uma escola com poucos alunos por classe. A diretora referia-se a ele como "doente", "coitadinho", e dizia que tinha "muito carinho" por ele. Tínhamos informações de que ele mantinha pouco contato com os meninos da classe. Isso nos preocupava pois, em nossas atividades, ele tinha dificuldade de ingressar no grupo de meninos em brincadeiras de parque, aparentemente por falta de vivência nessas situações. Entretanto, isso não se constituía em foco de preocupação da escola.

Fazíamos constantes sugestões à mãe, para que ele tivesse mais contatos com meninos de sua idade. Ela reclamava de vários problemas com os meninos da escola, e atribuía algumas dificuldades às mães dos meninos. Fizemos sugestões de que ele passasse a participar de algum esporte coletivo, desde que autorizado pelo neurologista. Depois de algum tempo, ela o colocou na natação, também por insistência do próprio Lúcio, e relatava que ele gostava muito. Mas, ao mesmo tempo, colocou-o em equoterapia, freqüentada por crianças com problemas muito acentuados. A equipe envolvida nesse atendimento tinha enviado mensagem para a escola, em um caderno também enviado a nós, em que se dispunha a ajudar na questão das dificuldades que Lúcio apresentava na escola.

As preocupações da mãe estavam centradas no rendimento escolar de Lúcio, e não em questões de entrosamento com colegas. E essas preocupações quanto ao rendimento não eram vistas como algo a ser encarado em seu 
aspecto pedagógico, mas sim como indicação de problemas orgânicos, para os quais buscava tratamento, mudando constantemente de neurologista, e buscando outros profissionais da área da saúde. Essas atitudes eram reforçadas pelo pediatra que o havia atendido desde o nascimento e que, no dizer da mãe, constantemente previa que Lúcio teria problemas no futuro.

A questão a ser salientada aqui é que se trata de um exemplo de "fabricação da deficiência", com a contribuição de vários agentes de saúde e educacionais, e da dificuldade de rompimento do círculo vicioso formado.

b) Oferta de compensações à criança, em virtude do problema:

Temos observado vários casos em que os familiares tendem a fazer as vontades da criança, e chegam a verbalizar que é por pena do problema que têm. Um exemplo é o de Beatriz, que ficou cega aos dois anos, em decorrência de tumores nos olhos. Ela mora com a mãe e os avós maternos, e estes últimos, declaradamente, dizem que fazem todas as suas vontades. A família tem renda acima de 10 salários mínimos. Beatriz está com seis anos, tem grande capacidade cognitiva, está na escola regular particular e recebe atenção especializada quanto a recursos educacionais para a deficiência visual. O foco de nossas atenções está em propiciar-lhe condições de interação social com parceiros, levando em conta a importância de relações com pares, e não apenas com adultos, no desenvolvimento social. Isso fica dificultado por sua posição habitual de exigência de privilégios, o oposto do esperado em relações com coetâneos. Além disso, sua postura autocentrada tem dificultado, em alguns momentos, sua interação com adultos mediadores, tais como professores, por sua expectativa de recebimento de atenção privilegiada. Sua mãe tem verbalizado esse tipo de preocupação, também em relação a situações ocorridas na comunidade. Relatou que, quando chega com Beatriz a um parquinho público e a leva para o balanço, as mães retiram as crianças do balanço, para que Beatriz possa ocupá-lo.

Temos, aqui, exemplo de uma prática bastante observada, nem sempre de forma tão explícita, e que pode trazer problemas para o desenvolvimento da criança. Um esclarecimento do profissional quanto aos riscos dessa prática pode contribuir para reduzir sua ocorrência. Em casos mais persistentes, esse esclarecimento não será efetivado em apenas uma entrevista, e novas orientações serão necessárias. Trata-se de medida importante, de esclarecimento aos responsáveis sobre os riscos da "compensação". A contribuição reside na redução de um problema secundário à deficiência: a "chatice" da criança. Uma criança cega não se torna "chata" perante os colegas porque é cega, mas porque é mimada e não aceita as regras que regulam as relações entre pares. 
c) Não aceitação dos limites momentâneos da criança, quanto à possibilidade de aquisições específicas (o que não significa a impossibilidade dessa aquisição)

Entre os clichês freqüentes entre os profissionais que atuam na área, são bastante comuns as afirmações sobre "respeitar o ritmo da criança" e "não fazer comparações com outras crianças". Isso é mais fácil de falar que de fazer.

Um exemplo é o caso de Karina, com diagnóstico de baixa visão severa, microcefalia, epilepsia (convulsões freqüentes na primeira infância e controladas, com alguns episódios, a partir dos cinco anos), e malformação do sistema nervoso central (SNC). Morava com os pais e perto dos avós. A família tinha renda acima de 10 salários mínimos. Karina participou de nossos grupos dos nove aos doze anos. Nesse período, estudava em escola particular que tinha uma proposta inclusiva. Estava matriculada na turma de sua faixa etária, da $2^{\mathrm{a}}$ até a $4^{\mathrm{a}}$ série, e a professora procurava incluí-la nas atividades curriculares, sugerindo tarefas que ela tivesse condições de cumprir (por exemplo, desenhar uma cena relativa à História do Brasil enquanto os colegas escreviam). Na última avaliação realizada em nosso projeto, Karina escrevia seu nome, às vezes omitindo alguma letra, reconhecia várias letras e palavras, por sua configuração geral, mas não realizava leitura de palavras completas, apresentava contagem com correspondência até 10 , com algumas falhas.

A participação de Karina nos grupos caracterizou-se, especialmente no início, por negações de participação em tarefas semelhantes às escolares, e por agressões físicas e verbais aos colegas. Aos poucos, houve uma redução nessas manifestações, e, ao mesmo tempo, ela começou a mostrar aquisições, especialmente em desenho, progressivamente mais reconhecível e elaborado, e em brincadeiras faz-de-conta, em que assumia diferentes papéis. Nossa hipótese é de que ela mostrou melhora em suas capacidades de representação, exatamente nos aspectos em que era menos pressionada. De fato, seus familiares eram muito preocupados com suas aquisições acadêmicas, centradas no ler, escrever e contar. Todas as noites, eram-lhe ministradas aulas relativas a essas habilidades, e era feita a lição de casa solicitada pela escola, mesmo com o desencorajamento nosso e da escola quanto a esse tipo de interação (ensino formal pelos familiares, à noite, quando todos estavam cansados). A escola considerava que seria importante que Karina realizasse as lições de casa sozinha, inclusive para aferir o que ela estava sendo capaz de apreender daquilo que era trabalhado em sala. E nós considerávamos que, provavelmente, parte da aversão pelas tarefas de leitura, escrita e contagem se devia, 
exatamente, a essa insistência dos familiares, contribuindo para interações com conflitos e brigas. Por outro lado, as aquisições relativas a outras formas de representação não eram valorizadas, mesmo quando explicadas por nós e justificada sua relevância no desenvolvimento infantil.

Consideramos que, no caso de Karina, temos, de um lado, a dificuldade da escola que, apesar de fazer mais do que outras escolas, não tinha (e não conhecemos escola que tenha) um sistema pedagógico que permitisse que uma criança com grandes dificuldades permanecesse em sala de aula regular, junto com colegas de $3^{\mathrm{a}}$ ou $4^{\mathrm{a}}$ série, com participação efetiva e com algum grau de aquisição acadêmica, mesmo que não comparáveis às dos colegas. Por outro lado, temos uma família que centrava seus objetivos nas aquisições do ler, escrever e contar, e que não conseguia ver significado em outras aquisições. É de se ressaltar que a família recebia orientações em nosso projeto, e, também, de outra psicóloga especializada em orientação familiar.

Do ponto de vista educacional, não temos visto o desenvolvimento de estratégias para a atenção a crianças com defasagens significativas, em modelos inclusivos de organização escolar. Consideramos, aliás, que inclusão escolar se constitui em meta, e não em estratégia de organização escolar. E que não significa, necessariamente, que a atenção à criança com dificuldades seja oferecia na classe comum, em conjunto com as crianças sem dificuldade.

Do ponto de vista da família de Karina, consideramos que sua postura, ao não encorajar suas aquisições, e ao montar situações autoritárias de ensino, contribuíam para suas dificuldades de aprendizagem. Estas não poderiam ser tributadas exclusivamente aos problemas neurológicos e visuais de Karina, uma vez que as relações da menina com as atividades escolares tinham construído uma história de aversão e fuga a elas. É isso que consideramos como não aceitação de limites momentâneos. Não queremos dizer que Karina não seria capaz de aprender a ler, escrever e contar. De fato, tínhamos indicação de que isso seria possível, embora, no período em que ela esteve participando de nossas atividades, isso estivesse difícil, mais pelos obstáculos criados pelas situações familiares e escolares, que por um impedimento real e definitivo, devido a seu estado orgânico. A ação dos familiares, de encorajar ou "forçar" a aprendizagem, tinha o efeito contrário, de dificultá-la.

Aqui se trata de analisar claramente a situação, e identificar os aspectos das relações interpessoais (principalmente familiares, no caso) e institucionais (organização do ensino nas escolas) que estavam ligados às dificuldades de Karina. Os problemas orgânicos eram irreversíveis, e estabeleciam um limite para sua aprendizagem. Entretanto, fatores ligados às interações cotidianas de Karina, com constantes exigências que ela não tinha condições de atender, 
e a falta de aprovação para suas aquisições, poderiam e deveriam ser explicitados, e teriam condições de contribuir para a alteração dessas relações. De fato, consideramos que, nesse caso, houve múltiplas tentativas, de diferentes profissionais, sem grande sucesso, o que mostra, também, os limites da intervenção profissional.

Mas fica a questão da identificação de alguns fatores que estariam contribuindo para o agravamento do quadro, no caso, as exigências incompatíveis com as condições presentes da criança. Trata-se, de novo, de construção da deficiência secundária, num caso em que a presença de fatores orgânicos poderia servir como explicação para os problemas observados, na falta de uma análise mais atenta dos fatores psicossociais e organizacionais (estrutura da escola) envolvidos.

\section{Considerações finais}

Os tópicos apresentados trouxeram exemplos em que a atuação profissional teve o papel de favorecer ou dificultar o processo de inclusão de pessoas com deficiência. Consideramos que as diferentes formas de atuação refletem diferentes concepções sobre desenvolvimento humano. De um lado, modelos de cunho organicista, em que o problema orgânico é visto como o principal determinante dos problemas de desenvolvimento observados na pessoa. De outro, modelos com ênfase nos aspectos psicológicos e sóciohistóricos, centrados no papel das interações estabelecidas na família, escola e comunidade, que representam práticas culturalmente estabelecidas, e que influenciam os modos de produzir ou reduzir as desvantagens decorrentes das deficiências e incapacidades (vYGOTSKY, 1934; 1997). Os modelos com foco nas influências ambientais são responsáveis tanto pelas formulações sobre a construção social da deficiência como pela ênfase nas estratégias para promoção do desenvolvimento e inclusão social de pessoas com problemas de origem orgânica. É essa a perspectiva que temos adotado, e a partir da qual discutimos a questão da intervenção no desenvolvimento psicológico de crianças com problemas orgânicos.

$\mathrm{Na}$ atuação de algumas equipes profissionais, observam-se posições que podem ser o reflexo da adoção de modelos organicistas de desenvolvimento. Assim, qualquer atividade de avaliação ou intervenção começa com o 
histórico do problema, mas não como base para uma análise das interações atuais, visando a modos de redução de desvantagens. $\mathrm{O}$ foco permanece no problema orgânico, detalhadamente visto e revisto, como um determinante onipresente, como uma nuvem que paira sobre a criança, como uma marca indelével que, de formas diretas ou sutis, influencia prognósticos e propostas de intervenção. Esses reflexos são observados nas práticas de avaliação e intervenção, das quais apresentamos alguns exemplos no presente trabalho.

Por outro lado, a adoção de modelos que enfatizem os aspectos psicológicos e sócio-históricos vai olhar para o histórico dos problemas orgânicos de outra forma, com a pergunta: dada essa condição, e dados os conhecimentos atuais sobre desenvolvimento humano (ex: importância da interação adulto-criança e das relações entre pares; importância da iniciativa, independência e autonomia, entre outros tópicos), como promovê-los nessa criança, com essa história de desenvolvimento?

Coloca-se aqui uma questão, relativa às propostas de intervenção no desenvolvimento de crianças com problemas orgânicos, realizadas por equipes multidisciplinares. Embora fundamentais, são insuficientes as orientações centradas na especificidade do problema (ex: informação sobre recursos especiais para leitura e escrita, discussão sobre respeito às diferenças, entre outros). Para cada criança e seu grupo de referência, observam-se modos específicos de interação e de concepção do problema, que resultam em modos específicos de manifestação de dificuldades. Sem uma plena compreensão de cada caso, podem passar desapercebidos certos modos de lidar com a criança que podem dificultar a superação das desvantagens (ex: a busca da família de Lúcio por novos neurologistas e modos de terapia, vista não só como zelo, mas também como parte de um modo de torná-lo mais doente do que efetivamente era; a preocupação da família de Karina com sua aprendizagem de leitura e escrita, não só como um interesse real em práticas socialmente valorizadas, mas também como uma dificuldade de valorização de outras aquisições de Karina). A questão que fica é de como organizar os serviços, de modo a favorecer a realização desse tipo de análise em serviços de saúde e educação, visando à promoção do desenvolvimento da criança com problemas orgânicos, na direção da inclusão social.

Não se trata de proposta de terapia individual dos casos. São bastante conhecidos e divulgados os modelos de atenção, preferencialmente em grupos, para organização de serviços de saúde, e, obviamente, de educação. Os próprios casos aqui apresentados são fruto de trabalho predominantemente em grupo, de crianças e de pais. Tampouco se trata de buscar, nos casos, os aspectos patológicos. Trata-se da identificação, em cada etapa do processo, 
dos meios mais adequados de promoção do desenvolvimento, especialmente em momentos críticos como o início da orientação aos pais sobre possibilidades da criança, a definição sobre tipo de escola e de recursos adicionais a serem buscados, o incentivo ao lazer com parceiros, a conquista de maiores graus de independência, entre outros.

Com um enfoque centrado em modos de encorajar o desenvolvimento, é possível obter resultados muito significativos, e evitar os prognósticos pessimistas, advindos de modelos organicistas. Se é verdade que se tem o risco da construção social da deficiência, é também verdade que podemos apostar na desconstrução da deficiência. A discussão sobre modos de fazê-lo constitui-se na tarefa dos que atuam na formulação e execução de políticas de saúde e educação.

\section{REFERÊNCIAS}

AMARAL, L. A. Deficiência: questões conceituais e alguns de seus desdobramentos. Cadernos de Psicologia, n. 1, p. 3-12, 1996.

BATISTA, C. G. Crianças com deficiência visual: como favorecer sua escolarização? Temas em Psicologia, v. 6, n. 3, p. 217-29, 1998.

BATISTA, C. G. Deficiência visual, alterações no desenvolvimento e o processo de escolarização. Boletim de Psicologia, L1, n. 115, p. 187-200, jul./dez. 2001.

BATISTA, C. G.; NUNES, S. S.; HORINO, L. E. Assisted assessment of cognitive abilities in children with organic problems: problems and possible solutions. In: OERS, B. van; WARDEKKER, W.; BLOM, S.; ELBERS, E.; POMPERT, B.; VEER, R. van der. (Orgs.). Book of abstracts: Dealing with Diversity, v. 4, n. 17, p. 458, 2002.

BUSSAB, V. S. R.; RIBEIRO, F. L. Biologicamente cultural. In: SOUZA, L.; FREITAS, M. F. Q.; RODRIGUES, M. M. P. (Orgs.). Psicologia: reflexões (im)pertinentes. São Paulo: Casa do Psicólogo, 1998.

LEMGRUBER, V.; PAINE, P. A. Adaptação brasileira da escala verbal do WISC. Arquivos Brasileiros de Psicologia, v. 33, n. 1-2, p. 32-56, jan./jun. 1981.

LIPSKY, D. K.; GARTNER, A. Inclusive education: a requirement of a democratic society. In: DANIELS, H.; GARNER, P. (Orgs.). Inclusive education- World Yearbook of Education 1999. Londres: Kogan Pb, 1999.

RODRÍGUEZ, C.; MORO, C. El mágico número tres: cuando los niños aún no hablan. Colección: Temas de Psicología. Barcelona: Paidós, 1999. 
ROSSETTI-FERREIRA, M. C. Interação entre fatores biológicos, sócio-econômicos e culturais no desenvolvimento mental e desempenho escolar da criança desnutrida. Cadernos de Pesquisa, v. 29, p. 37-48, jun. 1979.

VYGOTSKY, L. S. Obras escogidas, V-Fundamentos de Defectología. Madri: Visor, 1997. (tradução do original russo de 1983, coordenada por Zaporozhets, tradução de: J. G. Blank, revisão de N. J. V. Vargas e I. Filanova. Coletânea de textos originalmente produzidos até 1934).

WARREN, D. H. Blindness and Children: an individual differences approach. Cambridge: Cambridge University Press, 1994.

Texto recebido em 24 maio 2003 Texto aprovado em 28 ago. 2003 